\title{
La transformación del procedimiento administrativo y la LNPA (Ley Nacional de Procedimientos Administrativos)
}

\section{Administrative procedure transformation and the LNPA (Administrative Procedure National Law, Argentina)}

\section{JUAN CARLOS CASSAGNE"}

Resumen: El artículo parte de la premisa de que, si bien ya nadie discute si la administración puede regular el procedimiento administrativo, no se puede desconocer que el parlamento es el órgano competente para dictar las normas que reglamentan el ejercicio de los derechos de los ciudadanos frente a la administración. Seguidamente, el estudio realiza un análisis de la armonización entre el principio de competencia y los de legalidad y eficiencia, y la importancia de la participación de los ciudadanos en la toma de decisiones públicas las audiencias de este tipo. Finalmente, se desarrollan los principales aspectos de la relación entre el procedimiento administrativo y la tutela judicial efectiva, así como algunas nuevas funciones del procedimiento administrativo como la información y el consenso.

Palabras clave: Procedimiento administrativo - decisiones públicas - tutela judicial

Summary: This article starts from one assumption: while attribution of the Administration to regulate administrative procedures is not under discussion, competency of parliament to make rules, in order to regulate the exercise of citizen's rights facing Administration, can not also be ignored. Then, an analysis of harmonization among competition principle with legality and efficiency principles, also importance of citizen participation in public decisionmaking and public hearings, is carried out. Main aspects of relationship between administrative procedure and effective judicial guardianship and some new functions of administrative procedure, as information and consensus, have been finally developed in this article.

Key words: Administrative Procedure - public decisions - judicial guardianship

\footnotetext{
Es doctor en Derecho y Ciencias Sociales por la Universidad de Buenos Aires (UBA). Asimismo, es vicepresidente de la Academia Nacional de Derecho y Ciencias Sociales, donde se desempeña como especialista en Derecho administrativo, y presidente del Instituto de Derecho Administrativo de dicha corporación.
} 
CONTENIDO:I.INTRODUCCIÓN.-II.PROBLEMÁTICA COMPETENCIAL.-III.ARMONIZACIÓN ENTRE EL PRINCIPIO DE COMPETENCIA Y LOS DE LEGALIDAD Y EFICIENCIA.- IV. LA PARTICIPACIÓN DE LOS CIUDADANOS EN LA TOMA DE DECISIONES PÚBLICAS: LAS AUDIENCIAS PÚBLICAS.- V. EL PROCEDIMIENTO ADMINISTRATIVOY LA TUTELA JUDICIAL EFECTIVA. V.1.- LA FUNCIÓN DE GARANTÍA DEL PROCEDIMIENTO ADMINISTRATIVO Y LA TUTELA JUDICIAL EFECTIVA. V.2.- EL REQUISITO DEL AGOTAMIENTO DE LA VÍA ADMINISTRATIVA. V.3.- UN CAMBIO PARADIGMÁTICO: LA JURISPRUDENCIA DE LA CORTE SUPREMA DE JUSTICIA DE COSTA RICA. VI.- HACIA NUEVAS FUNCIONES DEL PROCEDIMIENTO ADMINISTRATIVO: LA INFORMACIÓNY EL CONSENSO.

\section{INTRODUCCIÓN}

En la medida que es hija de su tiempo, y, consecuentemente, de las ideas imperantes en una determinada época histórica, toda ley es temporal.

Las ideas nacen en el seno de las respectivas comunidades nacionales o supranacionales y, como son por naturaleza comunicables, pronto se expanden en los distintos ordenamientos, con lo que integran algo así como el tronco común de la estructura básica de los distintos derechos comparados.

La LNPA no se sustrajo al influjo de ese proceso comparatista y adoptó, en su momento, las principales innovaciones provenientes del Derecho de otros países y de la doctrina vernácula ${ }^{1}$. En ese entonces, se pensaba en el procedimiento administrativo en términos procesales; es decir, montado sobre una estructura bilateral que sostenía el principio contradictorio.

Pero las cosas han cambiado y, como vamos a ver, las transformaciones que se vienen operando en el procedimiento administrativo demandan una reforma, a fin de actualizar el ordenamiento con la recepción de nuevos instrumentos y fórmulas que encaucen la participación de los ciudadanos en la toma de decisiones públicas.

Algunos piensan que el proceso de transformación debe generar el cambio radical de las instituciones del procedimiento administrativo. Esta creencia, aparte de ignorar la naturaleza evolutiva del Derecho, implica una opción extrema y riesgosa que, al volcar el eje del sistema en la participación pública, produce la desintegración de los fines a los cuales el sistema debe servir para realizar el bien común o interés público.

Como la complejidad creciente de un sistema de participación de los ciudadanos conduce a un aumento de las libertades y de las

1 Así lo señalaron en la Exposición de Motivos los autores de la LNPA (Éscola, Cozzi y Young) al reconocer, principalmente, la influencia que proyectaron en la normativa las doctrinas de Marienhoff y Linares. 
posibilidades que tienen las personas para intervenir en las decisiones públicas, hay que cuidar de no caer en el desorden que termina destruyendo la necesaria cohesión del conjunto. El desorden extremo deja de ser fecundo, por lo que resulta imprescindible encontrar fórmulas de equilibrio que hagan posible realizar el ideal participativo en forma armónica y eficaz, sin degradar los derechos fundamentales de las personas, aunque se trate de minorías o de meros sujetos individuales.

Resulta evidente que la transformación del procedimiento administrativo no puede llevarse a cabo pasando por alto las garantías y principios del Estado de Derecho. De ese modo, la incorporación de las normas y fórmulas que traducen las nuevas tendencias transformadoras han de respetar, con carácter imperativo, la separación de poderes, las competencias y garantías del Estado constitucional, y, sobre todo, el principio de legalidad y el debido proceso adjetivo o tutela administrativa efectiva, además de todos los principios generales de carácter institucional típicos del procedimiento administrativo - como el formalismo, la economía, la celeridad, la sencillez y la eficacia, entre otros-.

Porque lo que la administración debe perseguir es, básicamente, la realización del interés público mediante el funcionamiento de una estructura humana que asegure una buena administración y su control, sin mengua de las otras finalidades que, modernamente, se considera debe cumplir a través del procedimiento administrativo².

\section{PROBLEMÁTICA COMPETENCIAL}

Si se mira la materia del procedimiento desde el ángulo competencial, es decir, a partir del conjunto de competencias atribuidas a una organización política, surgen una serie de cuestiones e interrogantes que los ordenamientos, así como la práctica o costumbre constitucional, han tratado de resolver.

Como primera observación puede advertirse que la caída del monopolio legiscentrista - la ley como centro absoluto del sistema normativo- ha generado tendencias favorables a la autorregulación del procedimiento administrativo por parte de los órganos ejecutivo y judicial, con lo que se ha invocado a la configuración de potestades autónomas organizativas que ciertamente encuentran sustento en la teoría de la división de los poderes $^{3}$.

2 Véase: TAWIL, Guido Santiago. «Sobre el futuro del procedimiento administrativo». Revista de Derecho Administrativo, número 9, 2010, pp. 11 y siguientes, Lima.

3 La afirmación del texto es válida en nuestro sistema constitucional aún cuando el modelo no haya seguido la versión francesa. Véase: Bosch, Jorge Tristán. ¿Tribunales judiciales o tribunales administrativos para juzgar a la administración? Buenos Aires: Editorial Zavalía, 1951, pp. 177 y siguientes.

LA

TRANSFORMACIÓN

DEL

PROCEDIMIENTO

ADMINISTRATIVO Y

LA LNPA

ADMINISTRATIVE

PROCEDURE

TRANSFORMATION

AND THE LNPA 
Ya casi nadie discute si la administración puede regular el procedimiento administrativo, ya sea por delegación o mediante reglamentos autónomos. Pero no se puede desconocer que el parlamento es el órgano competente para dictar las normas que reglamentan el ejercicio de los derechos de los ciudadanos frente a la administración, así como para consagrar las garantías y los principios que aseguran la protección efectiva de los derechos de las personas - tanto individuales como colectivas-.

Por otra parte, tampoco se puede ignorar que la administración pública posee potestades de auto-organización y que, consecuentemente, se halla habilitada para reglamentar los procedimientos que tramitan en su ámbito.

El escenario exhibe zonas grises y áreas de conflicto. En nuestra opinión, excepto las materias que integran la zona de reserva del legislador y las correspondientes a la del Ejecutivo, las potestades son concurrentes, con la salvedad de que si fueran ejercidas por el parlamento con anterioridad o a posteriori de las normas respectivas, debe prevalecer la ley del congreso sobre el reglamento del Ejecutivo, conforme al principio de jerarquía normativa que posee rango constitucional, según lo señala el artículo 31 de la Constitución Nacional.

\section{ARMONIZACIÓN ENTRE EL PRINCIPIO DE COMPETENCIA Y LOS DE LEGALIDAD Y EFICIENCIA}

La competencia constituye un requisito esencial que transforma a la validez de los actos y demás actuaciones comprendidas en un procedimiento administrativo. No se configura como un límite externo a la actuación de los entes u órganos administrativos, sino como un presupuesto de ella, en virtud de la vinculación positiva de la administración pública con el ordenamiento jurídico ${ }^{4}$.

Esa vinculación positiva deriva del principio de legalidad, de raíz constitucional ${ }^{5} \mathrm{y} \mathrm{legal}^{6}$, que predica que la competencia surge de principios y normas que integran una escala jerárquica compuesta por la Constitución, la ley o el reglamento.

A su vez, la naturaleza objetiva que caracteriza a la competencia no implica que ella no pueda surgir en forma implícita o, incluso, inherente, conforme al principio de especialidad. Sin embargo, la extensión de la competencia a lo inherente operada por el principio de especialidad, y su ejercicio, se encuentra interdicto en materia de actos de gravamen que,

4 «YPF c/ Enargas» (sala I C.N.ACAF-20-2-1996, La Ley, 1996-C-36).

5 Artículo 19 de la C.N.

6 Artículo 3 de la LNPA. 
en nuestro sistema constitucional, no pueden dictarse sino en virtud de competencias que surjan expresamente de las normas del ordenamiento positivo. En estos casos, el principio de la permisión expresa constituye la regla de acuerdo al principio de legalidad que rige en materia sancionatoria.

Pero fuera de los actos de gravamen, el principio de la especialidad se impone como una regla interna de los entes u órganos, la cual predica que los entes, una vez creados, poseen aptitud de dictar aquellos actos vinculados con el cumplimiento de sus fines fundamentales para hacer todo lo que no se halla expresamente prohibido — según el principio on-

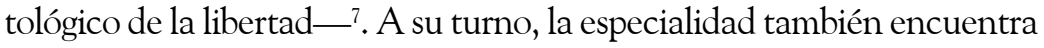
fundamento en el principio de eficacia, cuyo principal límite se halla en la ley y en la interdicción de arbitrariedad ${ }^{8}$.

\section{LA PARTICIPACIÓN DE LOS CIUDADANOS EN LA TOMA DE DECISIONES PÚBLICAS: LAS AUDIENCIAS PÚBLICAS}

La evolución operada en el seno del Estado de Derecho ha venido a ampliar sus postulados básicos con el reconocimiento - generalmente, por vía legislativa y, en algunos casos, constitucionales- del derecho de los ciudadanos a participar en la adopción de decisiones públicas.

El origen de esta tendencia se encuentra en los procedimientos de audiencia pública y en la elaboración de normas reglamentarias creadas en el Derecho estadounidense y generalizados más tarde en los diferentes Derechos europeos y latinoamericanos, particularmente en materia de servicios públicos.

Existe un debate acerca de si hay un derecho de participación plena de los ciudadanos para intervenir en los mecanismos de formación de los actos y reglamentos administrativos. No vamos a entrar ahora en esa discusión. Simplemente señalamos que, en los casos en que el derecho de participación deriva de la ley, este no puede conculcar el carácter representativo de nuestra forma de gobierno — según lo señala el artículo 1 de la Constitución Nacional (C.N.) —, ni la prohibición de que el pueblo se arrogue directamente el derecho a deliberar y a gobernar, pues, conforme al artículo 22 de la C.N., «el pueblo no delibera ni gobierna sino por medio de sus representantes y autoridades creadas por esta Constitución».

Esto es así porque, en nuestro sistema constitucional, el derecho de participación de los ciudadanos se reconoce solo en forma excepcional

7 LINARES, Juan Francisco. «La competencia y los postulados de la permisión». RADA, número 2. Buenos Aires: Editorial Museo Social Argentino, 1971, pp. 14 y siguientes.

8 Véase: CASSAGNE, Juan Carlos. El principio de legalidad y el control judicial de la discrecionalidad administrativa. Buenos Aires: Marcial Pons, 2009, pp. 115 y siguientes.

\section{LA}

TRANSFORMACIÓN

DEL

PROCEDIMIENTO

ADMINISTRATIVO Y

LA LNPA

ADMINISTRATIVE

PROCEDURE

TRANSFORMATION

AND THE LNPA 
en los supuestos del derecho de iniciativa para presentar proyectos de leyes —según indica el artículo 39 de la C.N.—- y de consulta popular vinculante —según el artículo 40 de la C.N.—, lo que no altera el carácter representativo que, como principio general, tipifica la forma de gobierno adoptada por la Constitución. Se trata de fórmulas de democracia semidirecta que, al admitirse de esa manera excepcional, resultan de interpretación restrictiva ${ }^{9}$.

El ordenamiento legal positivo argentino no ha regulado la participación pública en los procesos de elaboración de disposiciones de naturaleza reglamentaria ${ }^{10}$, situación que es pasible de objeciones toda vez que, sin atribuir carácter vinculante a la participación -y sin resentir, por tanto, el carácter representativo del sistema de gobierno_-, puede favorecer la información recíproca — tanto del Estado como de los ciudadanos) - y contribuir a que se alcancen consensos sociales que darían mayor legitimidad a las normas.

Una tendencia distinta ha sido seguida en materia de audiencias públicas en los servicios públicos o en las actividades de interés público.

Como es sabido, si bien no existe a nivel constitucional norma alguna que lo recepcione, este procedimiento de audiencia pública ${ }^{11}$ fue instaurado en nuestro país en el ámbito de los entes reguladores del gas ${ }^{12}$, electricidad ${ }^{13} y$ telecomunicaciones ${ }^{14}$.

Se trata de un procedimiento administrativo strictu sensu, y los principios que lo rigen pueden resumirse en los de publicidad, transparencia ${ }^{15}$ y participación. A su turno, estos principios se proyectan al régimen que requiere de la oralidad y de la inmediación, del informalismo, de la contradicción, de la imparcialidad y de un adecuado reconocimiento de la legitimación de los participantes — concesionarios o licenciatarios, usuarios, contratistas, funcionarios públicos, entre otros-.

9 BADENI, Gregorio. Tratado de Derecho constitucional. Tercera edición. Tomo I. Buenos Aires: La Ley, 2010, p. 610.

10 Como ha sido la tendencia seguida por el Derecho estadounidense, ver al respecto: STRAUSS, Peter L. "Los procedimientos de elaboración de reglamentos y disposiciones administrativas en EE.UU.». En Javier Barnes (director). La transformación del procedimiento administrativo. Sevilla: Editorial Derecho Global, 2008, pp. 319 y siguientes.

11 Hutchinson sostiene que la expresión «audiencia pública» es equívoca en lo que hace a su significado, ya que, en unos casos, designa las formalidades a través de las cuales las partes de un procedimiento acceden a la actuación de la garantía constitucional de la inviolabilidad de la defensa en juicio (artículo 18 de la C.N.), mientras que en otros se refiere a ciertas formalidades de participación de los interesados en el proceso de ejercicio de la potestad reglamentaria por parte de los órganos investidos en esta. Solamente en este último caso cabría considerarla estrictamente como técnica participativa (HUTCHINSON, Tomás. «Algunas consideraciones sobre las audiencias públicas (una forma de participación ciudadana)". En Jornadas jurídicas sobre servicio público de electricidad. Buenos Aires, 1995, pp. 333 y siguientes).

12 Artículos $6,16,18,29,46,47,67$ y 68 de la ley 24.076 .

13 Artículos 11, 32, 46, 73 y 74 de la ley 24.065 .

14 SC res. 57/1996, BO, 3/9/1996.

15 Véase: LASSERRE, Bruno, Noëlle LENOIR y Bernard STIRN. La transparence administrative. París : Presses Universiaires de France, 1987. 
Las audiencias públicas pueden ser previas a un acto de alcance particular — y, en algunos casos, de naturaleza cuasijurisdiccional ${ }^{16}{ }^{16}$ o bien pueden formar parte del procedimiento para dictar o modificar normas reglamentarias ${ }^{17}$. La doctrina administrativa se ha postulado la obligatoriedad de observar este procedimiento en todos aquellos casos en que fuera necesario conceder una oportunidad de defensa a los afectados por el acto o proyecto de que se trate ${ }^{18}$.

Desde otro vértice, la jurisprudencia ${ }^{19}$ ha considerado que, con la nueva redacción del artículo 42 de la C.N., el artículo 30 1185/1990 — en tanto confería a la Comisión Nacional de Telecomunicaciones la facultad de celebrar una audiencia pública sobre aspectos de grave repercusión social- debía ser interpretado como obligatorio para la administración, ya que:

la realización de una audiencia pública no solo importa una garantía de razonabilidad para el usuario y un instrumento idóneo para la defensa de sus derechos, sino un mecanismo para la formación de consenso de la opinión pública, una garantía de transparencia de los procedimientos y un elemento de democratización del poder, sino -en lo que hace al sub examine- resultaría una vía con la que podrían contar los usuarios para ejercer su derecho de participación en los términos previstos en el invocado artículo 42, C.N., antes de una decisión trascendente.

Sin perjuicio de valorar la importancia que representa para los derechos de los usuarios el artículo 42 de la C.N., consideramos que no es posible extender la obligatoriedad de la celebración de audiencias públicas a los supuestos que la norma de carácter legal o reglamentaria no lo disponga con carácter expreso ${ }^{20}$, ya que, de lo contrario, se afectaría la seguridad jurídica de las decisiones que vaya a adoptar el ente regulador en materia de servicios públicos al poderse invalidar las resoluciones que fueron tomadas soslayando este procedimiento.

16 Artículos 11, 32, 73 y 74 de la ley 24.065, y artículos 6, 16, 18, 29, 67 y 68 de la ley 24.076.

17 Artículos 46 y 48 de la ley 24.065, y 46 y 47 de la ley 24.076 (ComADIRA, Julio R. «Reflexiones sobre la regulación de los servicios privatizados (con especial referencia al Enargas, ENRE, C.N.T y ETOSS)». En Derecho administrativo. Buenos Aires: Abeledo-Perrot, 1996, p. 249.

18 Gordillo, Agustín. Tratado de Derecho administrativo. Quinta edición. Tomo II. Buenos Aires: Fundación de Derecho administrativo, 1998, pp. 10-12. Sin embargo, en el Derecho estadounidense, la jurisprudencia de la Corte Suprema ha sentado la doctrina según la cual el derecho de participación activa de los ciudadanos no deriva de la Constitución (por ejemplo, en «City of Madison, Joint School District v. Wisconsin Employment Relations Comisión», 429 v.s., 167, especialmente p. 178 (1976), citado por SACRISTÁN, Estela. Las sesiones abiertas (open meeting) en el Derecho administrativo estadounidense como forma de publicidad de los actos estatales, tesina presentada en la Carrera de Especialización en Derecho Administrativo Económico de la Pontificia Universidad Católica Argentina. Buenos Aires, 1998, p.19.

19 C. Nac. Cont. Adm. Fed., Sala IV, in re «Youssefian, Martín v. Secretaría de Comunicaciones», del 23 de junio de 1998.

20 En este mismo sentido, véase FONROUGE, Máximo. «Las audiencias públicas». REDA, números 24 a 26. Buenos Aires: Depalma, 1997, pp. 185-186. 
Ahora bien, si la administración omite llevar a cabo una audiencia pública cuando esta fuera expresamente exigida por el ordenamiento, el acto o reglamento que se emita bajo esas circunstancias será nulo por violación al elemento forma del acto administrativo, el cual prescribe el cumplimiento de los procedimientos esenciales previstos para su emisión ${ }^{21}$.

Idéntica solución corresponderá en el supuesto de que el acto que se dicte con posterioridad a la celebración de la audiencia carezca de una motivación adecuada, no valore la prueba producida o no trate expresamente todos los hechos llevados a su conocimiento ${ }^{22}$.

\section{EL PROCEDIMIENTO ADMINISTRATIVO Y LA TUTELA JUDICIAL EFECTIVA \\ V.1. La función de garantía del procedimiento adminis- trativo y la tutela judicial efectiva}

La última función de garantía que persigue el establecimiento de reglas jurídicas que sirvan de cauce y canalicen el dictado de actos administrativos es la que le otorga al procedimiento administrativo una especial relevancia en el régimen del Estado del Derecho basado en la separación de poderes.

La Constitución de Argentina consagra la garantía de la defensa en juicio de los derechos — según su artículo 18- y prohíbe el ejercicio de funciones judiciales por parte del Poder Ejecutivo —-según su artículo 109-. Esa garantía integra la «tutela judicial efectiva», la cual no se limita al ámbito del Poder Judicial y que, al tener una naturaleza garantística extensiva, se proyecta al procedimiento administrativo ${ }^{23}$.

En ese escenario, configurado tras la jurisprudencia de la corte a partir del caso «Fernández Arias» y fallos posteriores concordantes, se desprende que:

[...] la jurisdicción judicial solo corresponde a los tribunales que integran el Poder Judicial de la Nación ${ }^{24}$, cuya cabeza es la Corte Suprema de Justicia;

[...] el acceso a la justicia no puede ser cercenado por obstáculos y ápices formales y los actos de las autoridades administrativas no constituyen

\footnotetext{
21 Artículo 7, inciso d, y artículo 14, inciso b de la LNPA. En este punto se debe tener en cuenta que la forma del acto se integra no solo con las formas de integración y con la voluntad, sino también con las referidas al procedimiento de formación de dicha voluntad y con las formas de publicidad. 22 Artículo 41 de la SC, res. 57/1996.

23 Ver al respecto: CANOSA, Armando N. Influencia del derecho a la tutela judicial efectiva en materia de agotamiento de la instancia administrativa. ED-166-988.

24 Principio que se desprende del caso «Fernández Arias», resuelto por la Corte Suprema de Justicia en el año 1960 (Fallos: 247:646).
} 
decisiones finales sino que están sujetos a revisión judicial ${ }^{25}$. El acceso a la justicia ha de ser irrestricto y efectivo como lo proclaman los artículos 8.1 y 25 de la Convención Americana de Derechos Humanos.

[...] el control de las decisiones administrativas debe ser suficiente ${ }^{26}$, con amplitud de debate y prueba.

[...] el tribunal que ejerce el control sobre la actividad administrativa ha de hallarse rodeado de garantías de imparcialidad e independencia ${ }^{27}$.

Como consecuencia del principio de la tutela judicial efectiva, y en directa conexión con el sistema de procedimientos administrativos, se plantean cuestiones jurídicas trascendentes para los derechos de las personas involucradas o afectadas por la actividad de la administración pública. Estas se centran en tres aspectos: el carácter facultativo que corresponde atribuir a la antigua regla que exigía, en todos los casos, el agotamiento de la instancia administrativa para poder demandar ante la justicia; en la innecesaridad del reclamo administrativo previo o, al menos, en su relativización, lo que abre paso a la demanda directa en supuestos en que no sea imprescindible el dictado de un acto administrativo previo como condición de acceso a la vía judicial; y, por último, en la necesidad de reinterpretar la función que cumplen los plazos de caducidad para acceder a la justicia.

A su vez, el procedimiento administrativo, al no establecer reglas que vinculen la acción estatal con el contenido de las sentencias judiciales, conduce muchas veces al quiebre de la tutela judicial efectiva ${ }^{28}$, con lo que se genera la paradoja de que a un particular le resulta más fácil obtener una sentencia de condena contra el Estado que conseguir que este cumpla con las resoluciones judiciales.

Ahora bien, en la última parte del siglo XX, aproximadamente desde hace treinta años, la tutela judicial efectiva ha cobrado gran relevancia en el plano jurídico gracias al impulso dado por la doctrina en España con motivo de su recepción constitucional.

Su proyección en Hispanoamérica, particularmente en la Argentina, fue notable, ya que el principio fue recogido tanto en la jurisprudencia de la Corte Suprema de Justicia de la Nación como en la Constitución de la Provincia de Buenos Aires del año 1994, aunque no siempre se han desprendido de él las consecuencias que cabe extraer en punto a

25 Aberastury, Pedro y María Rosa Cilurzo. Curso de procedimiento administrativo. Buenos Aires: Abeledo-Perrot, 1998 , pp. 19 y siguientes.

26 Fallos: 247:646 («Fernández Arias») y 311:334 («Di Salvo»)

27 Véase: ABERASTURY, Pedro yMaría Rosa CILURZO. Ob. cit., p. 22. Ahí se apunta que debe reconocerse la revolución que operó el caso «Fernández Arias».

28 PAREJO ALFONSO, Luciano. El procedimiento administrativo en España: situación actual y perspectivas de cambio. Ob. cit., pp. 466-468. Se apunta también a la necesidad de reformular el carácter revisor del control judicial y el mantenimiento de los plazos de caducidad establecidos para impugnar ante la justicia los actos administrativos. 
reafirmar la tendencia hacia un control judicial pleno y sin cortapisas de la actividad administrativa.

Nuestra Constitución, en línea con el molde de los antecedentes normativos y proyectos preconstitucionales, consagró en su artículo 18 la garantía de la inviolabilidad «de la defensa en juicio de las personas y de los derechos», siguiendo el Proyecto de Constitución para la Confederación Argentina elaborado por Alberdi ${ }^{29}$.

Esa garantía apuntaba, entonces, a brindar protección judicial a los derechos individuales y tendía a tutelar, fundamentalmente, la libertad de los ciudadanos, de manera que se configuraba uno de los ejes en los que se concretaba la filosofía constitucional.

En su evolución posterior, la garantía ${ }^{30}$ de la defensa fue completada con otras, tendientes a ampliar el círculo de los derechos protegidos originariamente por el artículo 18 de la Constitución Nacional. Tal es lo que ocurrió con el trasplante del debido proceso adjetivo proveniente del Derecho estadounidense ${ }^{31}$, y, modernamente, con el llamado «derecho a la jurisdicción».

Mientras el debido proceso adjetivo desarrolla positivamente la protección de los derechos a exponer y a plantear con amplitud las pretensiones en el proceso o procedimiento administrativo (derecho a ser oído), a ofrecer y producir la prueba conducente y a una decisión fundada que haga mérito de las principales cuestiones planteadas, el derecho a la jurisdicción reclama, simultáneamente, el derecho a ocurrir ante un juez en procura de justicia, a fin de obtener una sentencia justa y motivada susceptible de los recursos previstos en las leyes, junto con la exigencia de que el proceso se sustancie con rapidez, dentro de plazos razonables ${ }^{32}$.

29 En la parte primera, capítulo 2, el artículo 19 del Proyecto de Alberdi expresa que «el derecho de defensa judicial es inviolable».

30 Las garantías constitucionales constituyen medios tendientes a asegurar la protección de los derechos y a afianzar la seguridad jurídica. Actúan como instrumentos para contener el poder y lograr una buena administración. Han sido establecidas en el plano de las normas y principios de la Constitución nacional y de las leyes. Véase: LINARES, Juan Francisco. El debido proceso como garantía innominada en la Constitución Argentina. Razonabilidad de las leyes. Buenos Aires: Depalma, 1944, pp. 203-206; y LINARES QUINTANA. Segundo. Tratado de la ciencia del derecho constitucional y comparado. Primera edición. Tomo V. Buenos Aires: Alfa, 1953, p. 355. Para Carrió, cuando aludimos a las "formas de protección de los derechos", "queremos aludir a la acepción restringida de la palabra 'garantía' o sea la que se refiere a la posibilidad que tiene el titular de un derecho de poner en movimiento el aparato estatal, particularmente el jurisdiccional, a fin de que este actúe a su servicio y lo tutele" (CARRIÓ, Genaro. Recurso de amparo y técnica judicial. Buenos Aires: Abeledo Perrot, 1959, p. 28).

31 Véase: LINARES, Juan Francisco. Razonabilidad de las leyes. El "debido proceso" como garantía innominada en la Constitución Argentina. Segunda edición. Buenos Aires: Astrea, 1970, pp. 17 y siguientes.

32 BIDART CAmpos, Germán. Derecho constitucional. Tomo II. Buenos Aires: Ediar, 1969, pp. 473 y siguientes. 
Estas garantías, que la jurisprudencia de la Corte Suprema de Justicia de la Nación y la doctrina ${ }^{33}$ consideraron, en su momento, incluidas en la garantía del artículo 18 o vinculadas a ella, resultan sustancialmente potenciadas en virtud de la recepción de la tutela judicial efectiva, en el sentido que pasamos a exponer ${ }^{34}$ a continuación.

En efecto, no obstante la similitud que guardan las garantías constitucionales clásicas del ordenamiento constitucional argentino con la tutela judicial efectiva, esta última - como aconteció con la garantía constitucional innominada del debido proceso adjetivo ${ }^{35}$ - se caracteriza por su mayor amplitud no solo en el plano garantístico, sino también en cuanto a la protección del interés general en lo relativo a una buena administración ${ }^{36}$, sin dejar de descuidar, asimismo, el procedimiento administrativo ${ }^{37}$.

Los principales matices diferenciales comprenden tres aspectos. En lo fundamental, la tutela judicial efectiva apunta a la eliminación de las trabas que obstaculizan el acceso al proceso, así como también a impedir que, como consecuencia de los formalismos procesales, queden ámbitos de la actividad administrativa inmunes al control judicial, y, por último, tiende a asegurar el ejercicio pleno de la jurisdicción.

Resulta evidente que se trata de una garantía que armoniza de modo cabal con el reparto de funciones propio de la separación de poderes que ha instituido nuestra Constitución, al prescribir positivamente el sistema judicialista — según los artículos 116 y 117 de la Constitución nacional-, en el cual los jueces son los órganos encargados de resolver los conflictos entre los particulares y el Estado ${ }^{38}$.

En Argentina, antes de la moderna configuración del principio, un sector de la doctrina ${ }^{39}$ propició, en su momento, una serie de posturas que

33 Véase: «Alcaraz, Anatalia y otros c. Cía Sansinena SA» en fallos 247:246 (1950); y BIDART CAMPOS, Germán. Ob. cit., pp. 499-500.

34 Una postura contraria a la sustentada en el texto ha sido sostenida por Luqui en: LUQUI, Roberto Enrique. Revisión judicial de la actividad administrativa. Tomo I. Buenos Aires: Astrea, 2005, pp. 241 y siguientes. Esto sobre la base de que nada agrega de nuevo a la clásica garantía de la defensa en juicio que preceptúa el artículo 18 de la C.N. Sin embargo, ambas garantías guardan una relación de género y especie, en el sentido de que la tutela judicial efectiva comprende a la garantía de la defensa y, al propio tiempo, es más amplia, habida cuenta que tutela, entre otras cosas, el acceso a la justicia para que esta sea efectiva. En suma, se trata de una nueva categoría histórica que supera algunos dogmas antiguos, como el de la justicia revisora - en el contencioso administrativo-.

35 Artículo 1, inciso f de la LNPA.

36 FERNÁNDEZ, Tomás Ramón. "Juzgar a la administración contribuye también administrar mejor». REDA, números 15-16. Buenos Aires: Depalma, 1994, pp. 51 y siguientes.

37 CANOSA, Armando N. Ob. cit.

38 Un completo desarrollo del principio y las consecuencias que derivan de la adopción del sistema judicialista se encuentra en Bosch, Jorge Tristán. ¿Tribunales judiciales o tribunales administrativos para juzgar a la administración pública? Buenos Aires: Zavalía, 1951, pp. 36 y siguientes. Según este autor, la Constitución Argentina de 1853 representa, más que una ruptura con los antecedentes españoles, un salto adelante dentro de la línea evolutiva de las instituciones de la Metrópoli.

39 Véase: LINARES, Juan Francisco. "Lo contencioso administrativo en la justicia nacional federal», pp. 94-919 y siguientes, especialmente p. 926; GoRDILLO, Agustín. Tratado de Derecho administrativo. Volumen 2. Buenos Aires: Macchi, 1980, pp. 19-21 y siguientes. 
afirmaban la plenitud de la jurisdicción frente a las interpretaciones restrictivas que, con fundamento en las antiguas concepciones del contencioso-administrativo francés y español, propugnaban la limitación de los poderes del juez sobre la base de la naturaleza esencialmente revisora ${ }^{40}$ que atribuían a esta clase de jurisdicción — la cual era concebida como una jurisdicción de excepción-.

Recién en la última década algunos ordenamientos y la jurisprudencia - en forma limitada, por cierto- han comenzado a transitar por el camino correcto. Sin dejar de reconocer la influencia que ha tenido en esta evolución la obra de los juristas vernáculos, que actuaron como verdaderos pioneros en este campo para desterrar los ápices formales que caracterizaban el contencioso-administrativo de su época, no se puede menos que señalar la profunda gravitación que entre nosotros ha alcanzado la doctrina española a partir de la fundación de la Revista de Administración Pública (RAP) y de la publicación de las obras y trabajos científicos de sus juristas más eminentes ${ }^{41}$.

Tal como ha dicho González Pérez, «el derecho a la tutela judicial efectiva que se despliega, básicamente, en tres momentos diferentes del proceso (en el acceso a la jurisdicción, en el debido proceso y en la eficiencia de la sentencia) es, en definitiva, el derecho de toda persona a que se 'haga justicia', el cual se traduce, en el plano jurídico administrativo, en que siempre que crea que puede pretender algo con arreglo a Derecho frente a un ente público, tenga la seguridad de que su petición será atendida por unos órganos independientes y preparados» ${ }^{42}$.

\section{V.2. El requisito del agotamiento de la vía administrativa} En nuestro derecho procesal administrativo la situación era paradójica, ya que mientras en la Nación no estaba legislado el requisito del agotamiento de la vía administrativa para promover una demanda judicial contra el Estado y sus entidades hasta la sanción de la LNPA en el año 1972, las provincias y, particularmente, la provincia de Buenos Aires, exigían la previa denegación, la retardación o el agotamiento de la vía administrativa, según las respectivas regulaciones locales ${ }^{43}$. En la Nación, con anterioridad a la LNPA, el único requisito era la promoción de un reclamo administrativo previo (ley 3952).

40 FIORINI, Bartolomé. ¿Qué es el contencioso? Buenos Aires: Abeledo Perrot, 1965, p. 88.

41 GaRCíA DE ENTERRÍA, Eduardo. Hacia una nueva justicia administrativa. Segunda edición. Madrid: Civitas, 1992; GonZÁLEZ PÉREZ, Jesús. La reforma de la legislación procesal administrativa. Madrid: 1992; FERNÁNDEZ, Tomás Ramón. «Sobre el carácter revisor de la jurisdicción contenciosoadministrativa». Revista de Derecho Administrativo, 1976, p. 728.

42 González PÉREZ, Jesús. Comentarios a la Ley de la Jurisdicción Contencioso Administrativa. Tercera edición. Tomo I. Madrid: Civitas, 1998, p. 17.

43 Véase: HUTCHINSON, Tomás. «Mitos y realidades en el derecho administrativo argentino». En La Ley, 1989-C, 1071, especialmente pp. 1077 y siguientes. Según Hutchinson, la fuente a que acudió Varela al consagrar en «vía previa» no fue la ley Santamaría de Paredes, sino los antecedentes nacionales y provinciales anteriores (artículo 156, inciso 3, de la Constitución de la Provincia de Buenos Aires de 
Pero la situación continúa siendo paradójica, porque mientras que el Estado Federal ha establecido el requisito del agotamiento de la vía administrativa para poder impugnar ante la justicia un acto de alcance particular o general, con plazos de caducidad a los que la jurisprudencia y una parte de la doctrina les asigna un carácter fatal y perentorio ${ }^{44}$ con lo que se mantiene, para los otros supuestos, la figura del reclamo administrativo previo 45 -, por su lado, el nuevo Código Procesal de la Provincia de Buenos Aires ha acotado sustancialmente la procedencia de este recaudo procesal habilitante de la jurisdicción a solo dos supuestos, cosa que ha reducido la exigencia procesal al limitar los casos en los que la acción tuviere por objeto una pretensión anulatoria o resarcitoria -0 proveniente o vinculada con la invalidez de un acto administrativo- sin exigir el reclamo administrativo previo para los otros casos — excepto la pretensión prestacional (artículo 17 de la CPCA)—, cuya inutilidad ha sido debidamente destacada por la doctrina ${ }^{46}$.

\section{V.3. Un cambio paradigmático: la jurisprudencia de la Corte Suprema de Justicia de Costa Rica}

La Corte Suprema de Justicia de Costa Rica ha impuesto un giro copernicano al planteo tradicional que exhibía el derecho comparado - $\mathrm{y}$ que aún se mantiene en diversos ordenamientos-, el cual, sobre la base

1873). Aunque no es nuestro propósito polemizar con este distinguido autor, creemos que la norma de la Constitución de la Provincia de 1873 - que pasó a ser el artículo 157, inciso 3, en la reforma constitucional de 1889- no establecía el requisito del agotamiento de la vía administrativa, sino tan solo que hubiera "previa denegación de la autoridad administrativa». En realidad, esta exigencia aparece recién en el artículo 28, inciso 1, del Código de Varela de 1905, al prescribir como condición de admisibilidad del proceso contencioso administrativo que «la resolución sea definitiva y no haya recurso administrativo alguno contra ella». Este precepto fue, en rigor, el que impuso en la provincia el requisito del agotamiento de la vía administrativa. Cuadra apuntar también que, al referirse al carácter definitivo de la resolución administrativa y agregarle «que no haya recurso administrativo alguno contra ella», el citado código generó interpretaciones erróneas de la jurisprudencia provincial en punto a lo que se entiende por definitividad, comprendiendo en el concepto tanto las resoluciones que deciden el fondo del asunto como las que causan estado —es decir, las que agotan la vía administrativa-. Véase: VALLEFín, Carlos. Ob. cit., pp. 51 y siguientes. En la obra citada se mantiene el concepto amplio de «definitividad», aunque se distingue ambas categorías y, más aún, se las trata en forma separada como, por demás, corresponde a dos requisitos diferentes. Por su parte, la doctrina ha sostenido la distinción entre el concepto de acto definitivo y acto que causa estado en el sentido de que el primero es el que decide la cuestión de fondo finalmente mientras que el segundo es el que agota la vía administrativa de una situación contenciosa (LINARES, Juan Francisco. Derecho administrativo. Buenos Aires: Astrea, 1986, pp. 544-545). Al propio tiempo, hay autores como Soria que precisan más aún el concepto de acto definitivo, al sostener que son aquellos que «se exhiben de ordinario como el eslabón final de un encadenamiento de situaciones heterogéneas y no equivalentes que lo preceden y complementan» (SORIA, Daniel Fernando. «Los actos administrativos de trámite equiparables a definitivos y su impugnabilidad judicial». En La Ley, 1990-C, 947). La confusión o, si se quiere, la mezcla de conceptos, aparece en algunas obras de la antigua doctrina española, que probablemente habría seguido Varela (Véase: ABELLA, Fermín. Tratado teórico-práctico de lo contencioso-administrativo. Segunda edición. Madrid: Administración, 1888, p. 570).

44 GonZÁLEZ ARZAC, Rafael. «Los plazos de impugnación judicial de actos administrativos, ED, 51-955.

45 Artículos 30 a 32 de la LNPA, sin prescribir plazos de caducidad para la promoción de la demanda. Véase: ESTRADA, Juan Ramón. «Agotamiento de la vía administrativa y habilitación de la instancia judicial: dos importantes fallos de la Corte Suprema». REDA, número 4. Buenos Aires: Depalma, 1990, p. 323.

46 Entre los trabajos doctrinarios, cabe mencionar: GoRDILLO, Agustín. «El reclamo administrativo previo». En La Ley, 89-777. 
del reconocimiento de la llamada autotutela declarativa, legitimaba la exigencia de agotar la vía administrativa para poder acceder a la justicia, con fundamento en una serie de principios tales como eficacia, eficiencia y buena administración.

Si bien el legislador entendía que, con dicha exigencia, la propia administración podía defender el acto administrativo impugnado, declarar su invalidez o modificarlo - y así evitar comparecer ante la justicia-, lo cierto es que la regla del agotamiento se erigía en un formidable privilegio a favor de la administración que conculcaba el principio de igualdad de las cargas procesales y la tutela judicial efectiva.

En el caso «Fonseca Ledesma» ${ }^{47}$, la jurisprudencia de la sala constitucional de la Corte Suprema de Justicia de Costa Rica consideró que, a la luz de la supremacía de la Constitución y de la mayor jerarquía y vinculación de los derechos fundamentales - la corte habla de la eficacia expansiva y progresiva y de la interpretación más favorable - el carácter preceptivo u obligatorio de la regla «riñe con el derecho fundamental de los administrados a obtener una justicia pronta y cumplida - ex artículos 41 y 49 de la Constitución Política (tutela judicial efectiva) y con el principio de igualdad, puesto que -solo en el proceso contenciosoadministrativo- [...] se le obliga al justiciable, antes de acudir a la vía jurisdiccional [...]» el agotamiento de la vía administrativa, mediante la interposición de los recursos ordinario correspondientes.

El Alto Tribunal costarricense enfatiza en el sentido de que la violación de la tutela judicial efectiva deriva de los siguientes aspectos:

a. El hecho de que los recursos administrativos no logran que los superiores jerárquicos modifiquen o revoquen las decisiones adoptadas por los órganos inferiores. Puntualiza, al respecto, que es algo así como pretender «sacar agua de un pozo seco», transformado el procedimiento previo a la instancia judicial en una pesada carga para el administrado;

b. Las demoras que dilatan la decisión de fondo en el procedimiento administrativo, lo cual prolonga —en forma indefinida — el acceso a la justicia; $\mathrm{y}$,

c. La sumatoria de este último plazo (el necesario para agotar la vía administrativa) con el término de duración de los procesos en lo contencioso-administrativo, sumatoria que, en definitiva, genera una justicia tardía.

Adquiere relevancia, a su vez, la fundamentación concerniente al principio de igualdad, cuyo contenido refuerza la tesis garantística que se encuentra en la entraña del principio de la tutela judicial efectiva.

47 Se trató de un proceso ordinario promovido por William Fonseca Ledezma contra Gerardo Bolaños Alvarado, Claudia Reyes Silva y el Estado, que fue resuelto el 15 de marzo de 2006. 
$\mathrm{Al}$ respecto, la sala constitucional de la Corte Suprema de Justicia de Costa Rica señaló que:

En lo que atañe a la vulneración del principio de igualdad, debe indicarse que el agotamiento preceptivo de la vía administrativa, derivado del privilegio de la auto-tutela declarativa, expone al justiciable que litiga contra una administración pública a una situación discriminatoria, puesto que, no existe un motivo objetivo y razonable para someterlo a ese requisito obligatorio, a diferencia del resto de los órdenes jurisdiccionales. Debe tenerse en consideración que, incluso, la libertad de configuración o discrecionalidad legislativa al diseñar los diversos procesos, tiene como límite infranqueable el principio de igualdad. Lo anterior, queda reforzado si se considera que las administraciones públicas son un sujeto de Derecho más que no tienen por qué gozar de tales privilegios o prerrogativas y que el eje central en una administración prestacional o en un Estado Social y Democrático de Derecho lo es la persona, esto es, el usuario o consumidor de los bienes y servicios públicos. En esencia, los intereses públicos y la satisfacción de las necesidades colectivas no pueden tenerse como cláusulas de apoderamiento para enervar los derechos fundamentales de los administrados o, sencillamente, como el altar para ser sacrificados ${ }^{48}$.

La línea inaugurada por la Corte Suprema de Justicia de Costa Rica, mantenida en sentencias posteriores ${ }^{49}$, alcanzó consolidación parcial en el Código Procesal Contencioso administrativo de dicho país que entró en vigencia el 1 de enero de 2008. En este último ordenamiento, se sienta el carácter optativo de la regla del agotamiento como principio general que solo hace excepción en materia municipal y de contratación pública ${ }^{50}$.

En Argentina, muchos administrativistas se han volcado a favor de la tendencia a suprimir la regla del agotamiento de la vía administrativa o, al menos, atenuarla, basados en que su subsistencia conculca el principio de la tutela judicial efectiva, de base constitucional y supraconstitucional ${ }^{51}$.

Ese vuelco encuentra apoyo en la doctrina de la Comisión Interamericana de Derechos Humanos —en adelante CIDH— expuesta en el

48 Considerando V de la sentencia «Fonseca Ledezma».

49 Resoluciones 10.263 del 19 de junio de 2008 y 13.022 del 27 de agosto de 2008.

50 JIMÉNEZ MEZA, Manrique y otros. El nuevo proceso contencioso administrativo. Edición del Poder Judicial. San José: Escuela del Poder Judicial, 2006, p. 129. La cita corresponde a ZuÑIGA BOLAÑOS, Heidy. El agotamiento preceptivo de la vía administrativa en la contratación administrativa. San José: Universidad de Costa Rica.

51 AGUILAR VALDEZ, Oscar. «El agotamiento de la vía administrativa y la tutela judicial efectiva: una evaluación general del sistema de la ley 19.549 a treinta años de su vigencia». En la obra colectiva Juan Carlos Cassagne (director). Procedimiento y proceso administrativo. Buenos Aires: AbeledoPerrot, 2009, pp. 367 y siguientes.

\section{LA \\ TRANSFORMACIÓN DEL \\ PROCEDIMIENTO ADMINISTRATIVO Y LA LNPA \\ ADMINISTRATIVE PROCEDURE TRANSFORMATION AND THE LNPA}


caso «Palacios» ${ }^{52}$, en el que se sostuvo que la exigencia de un recurso de revocatoria ${ }^{53}$ contra un acto administrativo cuando de la máxima autoridad administrativa que había resuelto el fondo del asunto, conculca el derecho a la tutela judicial efectiva y al debido proceso, garantizado por los artículos 8 y 25 de la Convención Americana sobre Derechos Humanos ${ }^{54}$.

En conclusión, la $\mathrm{CIDH}$ - y en época reciente, de un modo más asertivo, la Corte Suprema de Costa Rica - ha consagrado su adhesión al nuevo paradigma. Esta última, en sintonía con la doctrina que venía bregando por la supresión o atenuación de la regla del agotamiento, declara que la mencionada regla es inconstitucional por violación de la tutela judicial efectiva y de otros principios constitucionales, como el de igualdad de cargas procesales, con lo que el requisito de agotar la instancia en el que descansaba el sistema ha pasado a ser opcional y no obligatorio o preceptivo. La consecuente primacía constitucional se ha impuesto así como los principios del Estado de Derecho. Más aún, han salido ganando los justiciables con esta nueva conquista del derecho público.

\section{HACIA NUEVAS FUNCIONES DEL PROCEDIMIENTO ADMINISTRATIVO: LA INFORMACIÓN Y EL CONSENSO} La concepción tradicional del procedimiento administrativo estaba anclada, casi exclusivamente, en un esquema de naturaleza procesal que ponía el acento en la estructura bilateral y en el principio contradictorio, sin abrir el cauce procedimental a los intereses colectivos de los ciudadanos. Ese esquema padecía el defecto de ignorar la participación pública en procedimientos de mayor uso o repercusión social como los que conciernen al planeamiento urbanístico, decisiones relativas a los servicios públicos y en general, en la elaboración de proyectos de leyes y de reglamentos. Tampoco se recogía el llamado derecho blando (soft law) o informal que se concreta en directivas y recomendaciones.

Las diversas leyes de procedimiento suelen no contemplar la realidad administrativa de nuestros días. Una realidad que exige que la

52 Informe de la CIDH 105/99, caso Palacios Narciso contra Argentina (10.194).

53 Requisito exigido por la jurisprudencia de la Suprema Corte de la Provincia de Buenos Aires.

54 Véase: BOTASSI, Carlos. "Habilitación de la instancia contencioso-administrativa y derechos humanos». En La Ley 2000-F-594. En la obra citada se anota, con acierto, que «la decisión de la $\mathrm{CIDH}$ posee una extraordinaria importancia porque denuncia la ilegitimidad de las trabas rituales, inconsecuentes y superfluas que impiden contar con una defensa efectiva de los derechos esenciales, o, en el mejor de los casos, postergan extraordinariamente los ya morosos trámites judiciales. Asuntos tales como la obligación de recurrir el acto definitivo emanado del órgano superior con competencia decisoria, los plazos breves de caducidad, la exigencia irrestricta del pago previo a la demanda judicial, la legitimación limitada a los titulares de derechos subjetivos, la invocación de actos de gobierno, institucionales o no justificables, la exclusión del control de discrecionalidad, y otras medidas y pseudoinstituciones restrictivas que aparecen en las leyes y en la jurisprudencia clásica, deben ser revisadas y ajustadas a la nueva realidad de las normas constitucionales». 
administración se transforme en un vehículo en el que confluyan y armonicen las exigencias del Estado de Derecho, la justicia, la ética pública y el principio de eficacia ${ }^{55}$.

Una de las funciones primordiales que cumple el procedimiento administrativo moderno es la de servir como instrumento para que se produzcan, en el seno de la administración, los intercambios de información necesarios ${ }^{56}$ para adoptar decisiones eficaces y para que se operen los consensos sociales que otorguen mayor legitimidad —en sentido político- al obrar administrativo.

En este sentido, el procedimiento administrativo precisa no solo incorporar mecanismos de negociación y participación informal, sino también instrumentar la participación formal de los ciudadanos en los procesos de elaboración de proyectos de leyes y reglamentos, así como en otros ámbitos y materias.

El procedimiento ha de enriquecerse con nuevas perspectivas que amplíen el ámbito del accionar administrativo a través de la participación de los ciudadanos en variados campos y sectores, sin desplazar los principios de legalidad y eficacia. Así, desde las autorregulaciones bajo control a posteriori, la cooperación interadministrativa, los procesos de gestión privada de las empresas públicas, la mediación, el derecho blando, el régimen de ética pública, la coordinación en red, las audiencias públicas, los procesos de elaboración de reglamentos y los procedimientos paccionados, son muchas las materias en las que se impone innovar en el procedimiento con nuevas fórmulas e instrumentos ${ }^{57}$.

Dentro de la línea expuesta, sin desplazar el eje en que se asienta, la arquitectura constitucional y legal del procedimiento administrativo precisa encontrar un adecuado equilibrio que permita armonizar los principios del Estado de Derecho - particularmente los de legalidad y eficacia - con la dimensión informadora y de consenso social que se procura con la transformación del procedimiento administrativo.

En suma, si la extensión del procedimiento administrativo configura una necesidad derivada del crecimiento exponencial que han tenido la información y la comunicación en el marco de las relaciones jurídicoadministrativas, el procedimiento administrativo constituye un instrumento útil para estructurar y asegurar la racionalidad ${ }^{58}$ en la toma de decisiones públicas.

LA TRANSFORMACIÓN DEL

PROCEDIMIENTO ADMINISTRATIVO Y LA LNPA

ADMINISTRATIVE PROCEDURE TRANSFORMATION AND THE LNPA 